\title{
A clinical and immunological study of children with chronic hepatitis $B$ virus infection
}

\author{
Mortada El-Shabrawi ${ }^{1}$, Manal Abdelgawad ${ }^{2}$, Ola Elgaddar ${ }^{3}$, Fetouh Hassanin ${ }^{4}$, Ahmed Khalil ${ }^{2}$, Aml Mahfouz $^{2}$, \\ Basant Elbanna² \\ ${ }^{1}$ Paediatric Department, Faculty of Medicine, Cairo University, Cairo, Egypt \\ ${ }^{2}$ Paediatric Department, Faculty of Medicine, Alexandria University, Alexandria, Egypt \\ ${ }^{3}$ Medical Research Institute, Alexandria University, Alexandria, Egypt \\ ${ }^{4}$ Misr International University, Cairo, Egypt
}

Gastroenterology Rev 2019; 14 (3): 211-216

DOI: https://doi.org/10.5114/pg.2019.88171

Key words: hepatitis, children, Egypt. Address for correspondence: Fetouh Hassanin, Misr International University, 11882 Cairo, Egypt, phone: +20 201006756257,
e-mail: fhassanin@aim.com

\begin{abstract}
Aim: To identify the clinical status and immunological profile of a cohort of children with chronic hepatitis B virus (HBV) infection to assess the short-term consequences of this infection.

Material and methods: This prospective case-control study included 30 children in the age range 1-15 years with positive HBsAg attending the Hepatology clinic of Alexandria University Children's Hospital. Twenty children received lamivudine $(3 \mathrm{mg} / \mathrm{kg}$, oral, once a day), and 10 children were lamivudine-resistant and received entecavir treatment (10-11 kg/0.3 mg to > $30 \mathrm{~kg} /$ $1 \mathrm{mg})$. They were followed up every 3 months for 1 year.

Results: The study showed that $97 \%$ of the studied cases were discovered accidentally during routine investigations and only $3 \%$ presented by acute hepatitis. Ninety percent of them had family member infection with HBV, of which $70 \%$ were the mother. Eighty-seven percent of cases had no clinical signs, and only $13 \%$ of cases had hepatomegaly. All of the cases were $\mathrm{HBsAg}$ positive, $50 \%$ were $\mathrm{HBeAg}$ positive, $56.7 \%$ were $\mathrm{HBeAb}$ positive, $33.3 \%$ were $\mathrm{HBcAb}$ positive, and $100 \%$ were $\mathrm{HBs} \mathrm{Ab}$ negative.

Conclusions: Most of children with HBV infection had associated family member infection and were accidentally discovered. Despite a marked decrease in HBV DNA level after treatment, there was no clearance of HBsAg and no HBsAb seroconversion. Screening for the HBsAb level in children with family members with HBV is recommended.
\end{abstract}

\section{Introduction}

Hepatitis B virus (HBV) infection remains a global public health problem, with changing epidemiology due to many factors such as vaccination policies and migration [1]. An estimated 240 million persons worldwide are chronic HBV surface antigen carriers [2]. The prevalence of chronic HBV infection varies geographically, from high (> $8 \%)$, through intermediate $(2-7 \%)$, to low (<2\%) prevalence [3]. The predominant routes of transmission vary according to the endemicity of the HBV infection. In areas with high HBV endemicity, the perinatal transmission is the main route of transmission [3, 4].

Although the incidence of HBV infection has dramatically declined since the implementation of uni- versal immunisation programs in many countries and blood-donor screening, a significant number of children are still infected every year, often developing chronic infection and requiring appropriate follow-up [4-6]. Most infected children are asymptomatic. Despite a rather benign course of chronic hepatitis B (CHB) during childhood and adolescence, $3-5 \%$ and $0.01-0.03 \%$ of chronic carriers develop cirrhosis or hepatocellular carcinoma, respectively, before adulthood $[7,8]$.

Failure of passive and active immunoprophylaxis in this setting may be the result of in utero transmission of HBV infection, perinatal transmission related to a high inoculum, and/or the presence of surface gene escape mutants [5, 6]. Vaccination is the most effective measure to prevent hepatitis B transmission. In highly 
endemic areas, it is also the most cost-effective medical intervention, offering a higher benefit-cost ratio, whereas in low-endemicity countries such cost-effectiveness is not as clear $[3,8]$.

\section{Aim}

The aim of the present work was to determine the clinical status and immunological profile of a cohort of Egyptian children with chronic hepatitis B viral infection, in order to assess the magnitude of this serious infection among the study group in the era of mass vaccination.

\section{Material and methods}

Study design: prospective study. Study type: case-control study. Study setting: Hepatology Unit of Alexandria University Children's Hospital. Target population: Thirty HBsAg-positive children in the age range 1-15 years attending the liver clinic of Alexandria University Children's Hospital. Thirty apparently healthy children (age and sex matching) served as the control group.

Data collection: Both case and control groups were evaluated as follows:

\section{Demographic data}

All patients were subjected to history taking using the questionnaire.

\section{Clinical examination}

General examination:

- Anthropometric measurements (weight, height, body mass index - BMI) for both groups;

- Signs of liver disease for cases (jaundice, pruritis, haematemesis, ascites);

Abdominal examination (liver span, size of the spleen, ascites).

\section{Laboratory investigations}

The following investigations were carried out for the cases:

- Routine investigations:

- Complete blood count.

- Tests of synthetic liver capacity including the serum level of albumin, prothrombin time (PT), partial thromboplastin time (PTT), and international normalised ratio (INR) [9].

- Tests of liver excretory functions based on measurement of serum concentrations of substances metabolised and transported by the liver, including endogenously produced compounds such as total serum bilirubin (TSB) and direct serum bilirubin (DSB) [10].

- Tests that detect liver injury based on measurement of serum levels of endogenous substances released from damaged hepatocytes, including alanine aminotransferase (ALT) and aspartate aminotransferase (AST) [11].

- Tests that detect impaired bile flow or cholestasis based on measurement of serum levels of endogenous substances released from damaged tissue, such as alkaline phosphatase (AP) [12] and $\gamma$-glutamyltransferase (GGT) [13].

- Specific investigations for HBV infection:

- Hepatitis B virus surface antigen (HBsAg) titre; the envelop protein of the virus [14].

- HBeAg titre; the major viral nucleocapsid core polypeptide, $\mathrm{HBeAg}$ is a marker for transmissibility and active viral load [15].

- Quantitative HBV-DNA by PCR [16].

- Investigations to determine the immunological state of chronic HBV infection:

- Quantitative hepatitis B surface antibodies (HBsAb) - an indicator for HBV immunity [17].

- Hepatitis B virus e antibody HBeAb [18].

- Hepatitis B virus core antibody (HBcAb) total [18].

The following investigations were done for the control group:

- $\mathrm{CBC}$

- Hepatitis B virus surface antigen (HBsAg) titre [14];

- Quantitative hepatitis B surface antibodies (HBsAb) [17].

All tests were done at the Clinical Pathology Department, Alexandria University Children's Hospital.

\section{Imaging study}

Abdominal ultrasonography was performed to all cases focusing on: the size and echogenicity of the liver, presence of hepatic steatosis, cirrhosis, hepatic fibrosis, splenomegaly, and ascites.

\section{Treatment}

All patients were given an antiviral drug. Twenty children received lamivudine $(3 \mathrm{mg} / \mathrm{kg}$, oral, once a day), 10 children were lamivudine resistant and received entecavir treatment ( $>2$ years and $>10 \mathrm{~kg}$ ) at a dosage based on their weight; (10-11 kg/0.3 mg to $>30 \mathrm{~kg} / 1 \mathrm{mg}$ ) according to the American Association for The Study of Liver diseases (AASLD) guidelines [4].

\section{Follow-up}

The studied cases were followed up every 6 months for 1 year for imaging study and all laboratory investigations. 


\section{Results}

Thirty children with positive HBsAg aged from 1 to 15 years were enrolled in this study $(66.7 \%$ males and $33.3 \%$ females). As for the age of the studied population, $63.3 \%$ were in the age group 10-15 years, median 11 years. Clinically, $87 \%$ of the studied cases had no clinical signs and only $13 \%$ had hepatomegaly; $96.7 \%$ of the cases were discovered accidentally during routine investigations, and only $3 \%$ were presented by acute hepatitis. The results of measuring ALT activity showed that $46.7 \%$ of the studied cases had elevated levels, $40 \%$ had ALT in the upper level of normal, and $13.3 \%$ had normal ALT. Regarding AST activity, $63.3 \%$ of the studied cases had elevated AST, $23.3 \%$ had normal AST, and only $13.3 \%$ had AST in the upper level of normal. All studied cases had normal GGT.

Ultrasound examination showed that $76.6 \%$ of the studied cases had no sonographic abnormalities, while $20 \%$ had hepatomegaly and increased echogenicity, and $3.3 \%$ had cirrhosis. We found that the $90 \%$ of the studied cases had a family member infection with HBV, mainly the mother, and $66.6 \%$ of the cases with maternal risk presented in the age group 10-15 years versus $28.5 \%$ in the age group 5-10 years. HBVeAg detection showed that $40 \%$ of the studied cases had HBVeAg-negative chronic hepatitis while $36.7 \%$ had HBVeAg-positive chronic hepatitis, only $10 \%$ had HBVeAg-negative chronic infection (inactive carrier) and $13 \%$ had HBVeAg-positive chronic infection (immunotolerant phase). Studying the HBV immunological stage showed that all the studied cases were HBsAg positive with negative HBsAb (Table I). Viral load varied widely among the studies cases. Many of the studied cases had initially very high viral load while $33.3 \%$ had initially very low DNA level (Table II). Ninety-seven percent of the studied cases were discovered accidentally during routine investigations, and only $3 \%$ presented by acute hepatitis. The HBsAb level was very low $(<2)$ in $93.3 \%$ of the studied cases. Although the lowest level of HBsAb was found in the age group 10-15 years, this was not significantly different (Table III).

$\mathrm{HBeAg}$ was present in $50 \%$ of the cases. Although $\mathrm{HBeAg}$ was negative in $52.6 \%$ of cases in the age group $10-15$ years and $\mathrm{HBeAg}$ was positive in $47.4 \%$ of cases in the age group 10-15 years, it was not a significant difference.

When measuring the viral load, $50 \%$ of the studied cases in the age group 5-10 years had higher levels of viraemia (high and very high level) versus $47 \%$ in the age group 10-15 years, but it was not statistically

Table I. HBV immunological stage of the studied cases $(n=30)$

\begin{tabular}{lcccc} 
& \multicolumn{2}{c}{ Positive } & \multicolumn{2}{c}{ Negative } \\
\cline { 2 - 5 } & $\boldsymbol{N}$ & $\%$ & $\boldsymbol{N}$ & $\%$ \\
\hline $\mathrm{HBsAg}$ & 30 & 100.0 & 0 & 0.0 \\
\hline $\mathrm{HBeAg}$ & 15 & 50.0 & 15 & 50.0 \\
\hline $\mathrm{HBcAb}$ & 10 & 33.3 & 20 & 66.7 \\
\hline $\mathrm{HBeAb}$ & 17 & 56.7 & 13 & 43.3 \\
\hline $\mathrm{HBsAb}$ & 0 & 0.0 & 30 & 100.0
\end{tabular}

Table II. Levels of viraemia in the studied cases $(n=30)$

\begin{tabular}{lcc} 
Levels of viraemia $[\mathrm{IU} / \mathrm{ml}]$ & $\boldsymbol{N}$ & $\%$ \\
\hline Very low $<10,000$ & 10 & 33.3 \\
\hline Low level 10,000-100,000 & 2 & 6.7 \\
\hline Intermediate level 100,000-1,000,000 & 3 & 10.0 \\
\hline High level 1,000,000-10,000,000 & 1 & 3.3 \\
\hline Very high level > 10,000,000 & 14 & 46.7
\end{tabular}

Table III. Correlation between age groups and HBsAb level

\begin{tabular}{|c|c|c|c|c|c|c|c|c|}
\hline \multirow[t]{3}{*}{ Parameter } & \multicolumn{6}{|c|}{ HBsAb level [mlU/ml] } & \multirow[t]{3}{*}{$\chi^{2}$} & \multirow[t]{3}{*}{${ }^{\mathrm{MC}} p$} \\
\hline & \multicolumn{2}{|c|}{$\begin{array}{c}<2 \\
(n=28)\end{array}$} & \multicolumn{2}{|c|}{$\begin{array}{c}2-4.9 \\
(n=1)\end{array}$} & \multicolumn{2}{|c|}{$\begin{array}{c}5-10 \\
(n=1)\end{array}$} & & \\
\hline & $N$ & $\%$ & $N$ & $\%$ & $N$ & $\%$ & & \\
\hline \multicolumn{9}{|l|}{ Age [years]: } \\
\hline 1 & 1 & 3.3 & 0 & 0.0 & 0 & 0.0 & 4.567 & 1.000 \\
\hline 5 & 10 & 33.3 & 0 & 0.0 & 0 & 0.0 & & \\
\hline $10-15$ & 17 & 56.7 & 1 & 3.3 & 1 & 3.3 & & \\
\hline Total & 28 & 93.3 & 1 & 3.3 & 1 & 3.3 & & \\
\hline
\end{tabular}


Table IV. Correlation between different risk factors and level of viraemia

\begin{tabular}{|c|c|c|c|c|c|c|c|c|c|c|}
\hline \multirow[t]{3}{*}{ Parameter } & \multicolumn{10}{|c|}{ Level of viraemia } \\
\hline & \multicolumn{2}{|c|}{$\begin{array}{l}\text { Very low } \\
<10,000 \\
(n=10)\end{array}$} & \multicolumn{2}{|c|}{$\begin{array}{c}\text { Low level } \\
10,000-100,000 \\
(n=2)\end{array}$} & \multicolumn{2}{|c|}{$\begin{array}{l}\text { Intermediate level } \\
100,000- \\
1,000,000 \\
(n=3)\end{array}$} & \multicolumn{2}{|c|}{$\begin{array}{l}\text { High level } \\
1,000,000- \\
10,000,000 \\
\quad(n=1)\end{array}$} & \multicolumn{2}{|c|}{$\begin{array}{c}\text { Very high level } \\
>10,000,000 \\
(n=14)\end{array}$} \\
\hline & $N$ & $\%$ & $N$ & $\%$ & $N$ & $\%$ & $N$ & $\%$ & $N$ & $\%$ \\
\hline \multicolumn{11}{|l|}{ Risk factors: } \\
\hline Family member infection & 9 & 33.3 & 2 & 7.4 & 2 & 7.4 & 1 & 3,7 & 13 & 48.1 \\
\hline Unknown & 0 & 0.0 & 0 & 0.0 & 1 & 33.3 & 0 & 0.0 & 0 & 0.0 \\
\hline Operation & 1 & 33.3 & 0 & 0.0 & 0 & 0.0 & 0 & 0.0 & 0 & 0.0 \\
\hline Transfusion & 0 & 0.0 & 0 & 0.0 & 0 & 0.0 & 0 & 0.0 & 1 & 33.3 \\
\hline$\chi^{2}\left({ }^{M x} p\right)$ & \multicolumn{10}{|c|}{$40.491^{\star}\left(0.008^{\star}\right)$} \\
\hline
\end{tabular}

significant. Studying the risk factors in relation to the level of viremia, $51.8 \%$ of the studied cases with family member infection had significantly higher levels of viral load (high and very high levels), versus $33.3 \%$ of the studied cases with other risk factors (Table IV). As for liver enzymes, $44.4 \%$ of the studied cases with an infected family member showed elevated ALT (versus $66.6 \%$ of the studied cases with other risk), and $40.7 \%$ of the cases with family member infection had ALT in the upper limit of normal (versus 33.3\% of the studied cases with other risk factors). Studying cases with risk factors other than family history, $33.3 \%$ of them showed higher levels of viraemia (high and very high levels) together with ALT in ULN, while $66.6 \%$ of them had lower levels of viral load (very low, low, and intermediate levels) associated with elevated ALT, suggesting an inverse relation between levels of viraemia and ALT level. When studying the association between HBeAg and ALT, 53.3\% of the studied cases who were HBeAg-positive had elevated $A L T$ versus $40 \%$ of the HBeAg-negative cases that showed ALT elevation, though no significant difference was observed. Also, there was a marked decrease in ALT level after 1 year of treatment with NA therapy, where $46.6 \%$ of the studied cases showed an initially elevated ALT; that percentage dropped to $23.3 \%$ after 1 year of treatment. In $13.3 \%$ the studied cases who initially had normal ALT, that percentage increased to $33.3 \%$ after 1 year of treatment. In summary, ALT showed a median of $18.5 \mathrm{IU} / \mathrm{L}$ (one-fold increase above normal) initially, versus $11 \mathrm{IU} / \mathrm{L}$ (ULN) after 1 year of treatment.

Viral loads showed a significant decrease after 1 year of treatment. The median viremia value was $5215 \times 10^{3}$ before treatment versus $10 \times 10^{3}$ after 1 year of treatment.
All the studied cases remain HBsAg positive after 1 year of treatment. Only one HBeAg-negative case became $\mathrm{HBeAg}$ positive upon follow-up, and none of the studied cases who was initially $\mathrm{HBeAg}$ positive cleared HBeAg on follow-up. $83.3 \%$ of the studied cases became $\mathrm{HBCAb}$ positive on follow-up after 1 year.

\section{Discussion}

The chance of chronicity of HBV infection depends on the age of primary HBV infection [2]. Chronic HBV infection occurs in more than $90 \%$ of infants who are infected perinatally. Among children exposed to HBV before 5 years of age, 25-50\% develop chronic HBV infection. In individuals with primary HBV infection in adulthood, 5-10\% will develop chronic HBV infection [8].

Three main strategies have been proven to be effective in preventing HBV infection. They are behaviour modification, passive immunoprophylaxis, and active immunisation [19]. The implementation of a mass HBV immunisation program has been recommended by the WHO since 1991, and has dramatically decreased the prevalence of HBV infection in many countries [4].

The clinical course of chronic HBV infection is influenced by age at primary infection, gender, transmission route, HBV genotype, and environmental factors. Chronic HBV infection is classified into four immunological phases: (I) the immune-tolerant phase; (II) immune-reactive phase ( $\mathrm{HBeAg}$-positive chronic hepatitis $\mathrm{B}$ ); (III) low replicative phase; and (IV) reactivation phase (HBeAg-negative chronic hepatitis B) [20].

In this study most of the patients were male $(66.7 \%)$, more than 10 years old (63\%), and from urban areas (83\%). A similar result was found by Lok and Lai [21]. The source of infection was identified in 29 cases 
(27 cases had an infected family member, the mother in 21 cases, 1 case had history of blood transfusion, and one case had a surgical history) while 1 case had no evident source of infection. Family history of hepatitis $B$ is the commonest risk factor in acquiring infection in the studied children (90\%). Similarly to the present study Bortolotti et al. [22] found that 36 cases had family member infection (of those, eight cases were the mother during delivery), 3 cases had a history of transfusion, and 37 cases had no evident source of infection.

Contradictory to our result, Rukunuzzaman and Afroza [23], in their study on risk factors of hepatitis $B$ virus infection in children, considered maternal risk factor as one (but not the commonest) cause. In the present study, the family risk factor was via direct contact, not only through vertical transmission.

Almost all patients had no clinical signs, except 4 patients who presented with hepatomegaly (13.3\%), which was accidentally discovered in $96.7 \%$ of them. Lok and Lai [21] in their study also revealed that hepatomegaly was the only abnormal finding upon examination, being present in 5 children initially. Also, Boxall et al. [24], in their studies on the natural history of hepatitis B in infected carriers, demonstrated that all children were asymptomatic with normal physical examination, growth, and development, probably because their studied cases were carriers. On the other hand, Maggiore et al. [25], in their study on chronic HBV hepatitis in children, found that all patients were anicteric, and hepatomegaly was detected in 15 patients, and this was associated with splenomegaly in 2 patients.

Similarly, Bosch et al. [26], in their study on chronic viral hepatitis B in childhood, found hepatomegaly in $50 \%$ of their 26 studied cases and splenomegaly in 25\% of them.

The difference between our study and previous studies may be due to our classification of the studied cases into four categories; HBeAg-negative chronic hepatitis (40\%), HBeAg-positive chronic hepatitis (36.7\%), inactive carrier (10\%), and immunotolerant (13\%).

Initial laboratory investigations of the studied cases revealed that 26 patients had elevated ALT (86.6\%) and AST while GGT albumin, PT, and INR were normal in all the studied cases. In contrast to our findings, Lok and Lai [21] in their study found that serum ALT levels were normal in $80 \%$ of the children at presentation and remained within the normal range during the study in $60 \%$ of the cases. This finding may be due to the fact that all cases studied by Lok and Lai [21] were carriers with low level of viraemia.

After evaluation of the hepatitis B profile of the studied population, all patients had HBsAg and 50\% were positive for $\mathrm{HBeAg}$ with different levels of viraemia. Lok and Lai [21] stated that $84 \%$ of their studied population were initially positive for $\mathrm{HBeAg}$, and Lok and Lai [21] and Maggiore et al. [25] in their study on 29 children showed evidence of complete viral replication (HBeAg positive) in 24 cases, and incomplete replication (HBeAb positive) in five cases. The large number of HBeAg-positive patients in the previous studies could be attributed to the young age of the patients at presentation, so there was no seroconversion. Infection with hepatitis $B$ virus (HBV) remains an important global public health problem. Children with HBV infection need follow-up for several years, treatment when indicated, and follow-up for viral profile after treatment.

\section{Conclusions}

From the present study we concluded that HBV infection is present in the paediatric age group despite the application of compulsory HBV vaccination. Most children with HBV infection have associated family member infection. The majority of children with HBV infection are accidentally discovered due to the absence of clinical features. Despite a marked decrease in ALT levels and HBV DNA levels after treatment, no clearance of HBsAg and no HBsAb seroconversion was observed.

Recommendation: Screening of HBV infection is important in high-risk children, especially those with an infected family member. Vaccine should be given if levels of HBsAb are not protective.

A national program for screening for HBV infection in pregnant women is a mandate in Egypt. Most risk factors for maternal HBV acquisition were related to medical care, which calls for a re-enforcement of infection control practices in medical facilities.

\section{Conflict of interest}

The authors declare no conflict of interest.

\section{References}

1. European Association for the Study of the Liver. EASL Clinical Practice Guidelines: Management of chronic hepatitis B virus infection. J Hepatology 2012; 57: 167-85.

2. Schweitzer A, Home J, Micolajczyk RT, et al. Estimation of worldwide prevalence of chronic hepatitis B virus infection. A systemic review of data published between 1965 and 2013. Lancet 2015; 386: 1546-55.

3. Hou J, Liu Z, Gu F. Epidemiology and prevention of hepatitis B virus infection. Int J Med Sci 2005; 2: 50-7.

4. Haruki K, Ayano I Tomoo F. Pediatric hepatitis B treatment. Ann Transl Med 2017; 5: 37.

5. El-Karaksy HM, Mohsen LM, Saleh DA, et al. Applicability and efficacy of a model for prevention of perinatal transmission of hepatitis B virus infection: Single center study in Egypt. World J Gastroenterol 2014; 20: 17075-83. 
6. Ott JJ, Stevens GA, Groeger J, Wiersma ST. Global epidemiology of hepatitis B virus infection: new estimates of age-specific HBsAg seroprevalence and endemicity. Vaccine 2012; 30: 2212-9.

7. Ott J, Horn J, Krause G, Mikolajczyk RT. Time trends of chronic HBV infection over prior decades - a global analysis. J Hepatol 2017; 66: 48-54.

8. Stanaway JD, Flaxman AD, Naghavi M, et al. The global burden of viral hepatitis from 1990 to 2013: findings from the Global Burden of Disease Study 2013. Lancet 2016; 388: 1081-8.

9. Green RM, Flamm S. American Gastroenterological Association technical review on the evaluation of liver chemistry tests. Gastroenterology 2002; 123: 1367-84.

10. Chopra S, Griffin PH. Laboratory tests and diagnostic procedures in evaluation of liver disease. Am J Med 1985; 79: 221-30.

11. Giannini EG, Testa R, Savarino V. Liver enzymes alteration: a guide for clinicians. Can Med Assoc J 2005; 172: 367-79.

12. Kaplan MM, Alkaline phosphatase. Gastroenterology 1992; 62: 452-68.

13. Cabrera-Abreu JC, Green A. Gamma-glutamyltransferase: value of its measurement in pediatrics. Ann Clin Biochem 2002: 39: 22-5.

14. Yang R, Song G, Guan W, et al. The Lumipulse G HBsAg-Quant assay for screening and quantification of the hepatitis $B$ surface antigen. J Virol Methods 2016; 228: 39-47.

15. Wang Z, Zhang J, Yang $\mathrm{H}$, et al. Quantitative analysis of HBV DNA level and $\mathrm{HBeAg}$ titer in hepatitis B surface antigen positive mothers and their babies: $\mathrm{HBeAg}$ passage through the placenta and the rate of decay in babies. J Med Virol 2003; 71: 360-6.

16. Wang GH, Seeger C. The reverse transcriptase of hepatitis-B virus acts as protein primer for viral DNA synthesis. Cell 1992 71: 663-70.

17. Levrero $M$, Stemler M, Pasquinelli C, et al. Significance of antiHBs antibodies in hepatitis B virus infection. Hepatology 1991; 13: 143-9.

18. $\mathrm{Ni} \mathrm{YH}$, Chang $\mathrm{MH}$, Chen PJ, et al. Viremia profiles in children with chronic hepatitis $B$ virus infection and spontaneous e antigen seroconversion. Gastroenterology 2007; 132: 2340-5.

19. Sokal EM, Paganelli M, Wirth S, et al. Management of chronic hepatitis B in childhood: ESPGHAN clinical practice guidelines: consensus of an expert panel on behalf of the European Society of Pediatric Gastroenterology, Hepatology and Nutrition. J Hepatol 2013; 59: 814-29.

20. Fattovich G, Bortolotti F, Donato F. Natural history of chronic hepatitis B: special emphasis on disease progression and prognostic factors. J Hepatol 2008; 48: 335-52.

21. Lok AS, Lai CL. A longitudinal follow-up of asymptomatic hepatitis B surface antigen-positive Chinese children. Hepatology 1988; 8: 1130-9.

22. Bortolotti F, Cadrobbi P, Crivellaro C, et al. Long-term outcome of chronic type $B$ hepatitis in patients who acquire hepatitis $\mathrm{B}$ virus infection in childhood. Gastroenterology 1990; 99: 805-10.

23. Rukunuzzaman M, Afroza A. Risk factors of hepatitis B virus infection in children. Mymensingh Med J 2011; 20: 700-82.

24. Boxall E, Sira J, Standish R, et al. Natural history of hepatitis B in perinatally infected carriers. Arch Dis Childhood Fetal Neonatal 2004; 89: 456-60.
25. Maggiore G, Marzani D, De CG, et al. Chronic HB virus hepatitis in children. A study of 29 cases. La Semaine des Hopitaux 1984; 60: 1349-52.

26. Bosch C, Becker M, Rotthauwe HW, Födisch HJ. Chronic viral hepatitis B in childhood. I. Clinical, biochemical and histological results. Eur J Pediatr 1980; 135: 169-73.

Received: 27.06.2018

Accepted: 14.02 .2019 